\title{
Raman Spectroscopy as a Cultural Heritage Forensic Tool
}

\author{
CATARINA MIGUEL ${ }^{\mathrm{a}}$ AND ANTÓNIO CANDEIAS*a,b
}

${ }^{a}$ Laboratório HERCULES, Universidade de Évora, Largo Marquês de Marialva 8, 7000-676 Évora, Portugal; ${ }^{\mathrm{b}}$ Departamento de Química, Escola de Ciência e Tecnologia, Universidade de Évora, Rua Romão Ramalho, 59, 7000-671 Évora, Portugal

*E-mail: candeias@uevora.pt

\subsection{Unveiling the Authenticity of an Artwork Destroyed by a Fire}

Unveiling the originality of an artwork destroyed by a fire is a challenging task. The subject of this study combined a fire that occurred in a church at Christmas Eve, a police investigation on a possible loss of a Portuguese 17th century painting and the study of its presence during the fire based on its ashes. Asked by an insurance company of the possibility of the original painting having been replaced by a fake 21st century painting at the time of the fire's ignition, it was important to evaluate the originality of the materials present on the ashes resulting from the burnt painting, either from the original or as resultant heating products. In this sense, a multi-analytical approach was envisaged gathering optical microscopy (OM), ${ }^{\dagger}$ scanning

\footnotetext{
${ }^{\dagger}$ A Leica M205C stereomicroscope with a zoom range of $7.8 \times$ to $160 \times$ equipped with a Leica DFC295 camera and external illumination by optical fibres was used for examination of the ashes' cross sections.
}

Raman Spectroscopy in Archaeology and Art History Volume 2

Edited by Peter Vandenabeele and Howell Edwards

(C) The Royal Society of Chemistry 2019

Published by the Royal Society of Chemistry, www.rsc.org 


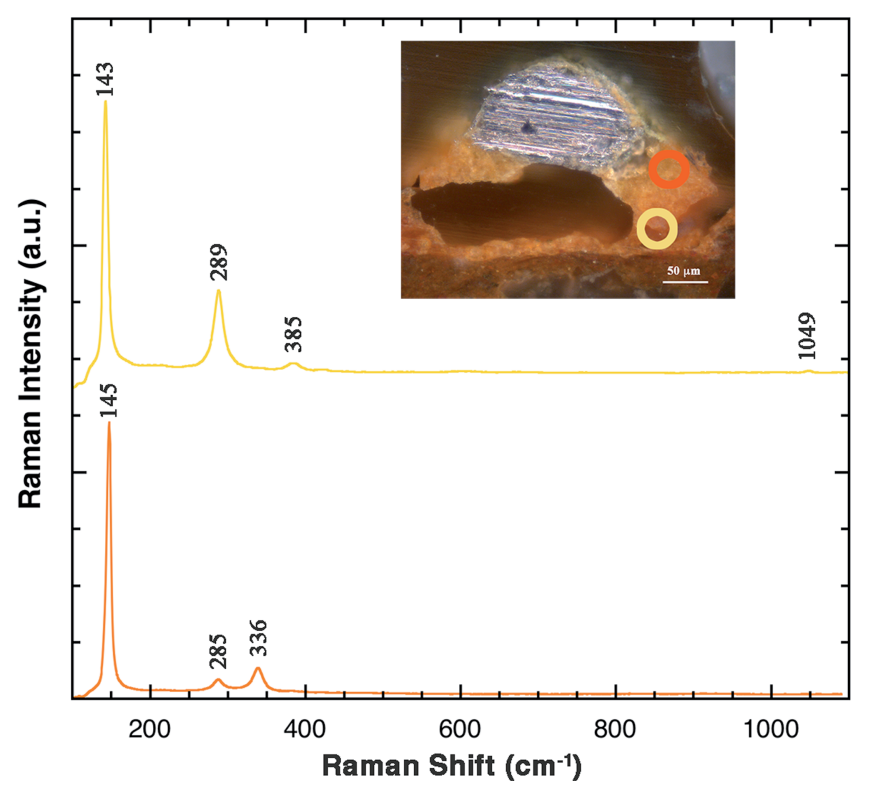

Figure 13.1 RM spectra of two spot analysis of a sample of ashes resulting from the burnt painting mounted as cross sections, where characteristic Raman bands of lead white $\left(1049 \mathrm{~cm}^{-1}\right)$, massicot $(143,289$ and 385 $\mathrm{cm}^{-1}$ ) and litharge $\left(145,285\right.$ and $\left.336 \mathrm{~cm}^{-1}\right)$ were identified. The inset shows a detail of the cross section and the analysed spots.

electron microscopy coupled with energy dispersive X-ray spectrometry (SEM-EDS) ${ }^{\ddagger}$ and Raman microscopy (RM). Raman microscopy ${ }^{\S}$ was used with the aim of identifying traces of materials contemporary to the painting's production and/or materials produced after the 17th century. RM spot analysis of several samples of ashes mounted as cross sections enabled us to identify the characteristic Raman bands of lead white (a lead carbonate hydroxide, $2 \mathrm{PbCO}_{3} \cdot \mathrm{Pb}(\mathrm{OH})_{2}$ ), massicot $(\alpha-\mathrm{PbO}$, orthorhombic crystal structure) and litharge ( $\beta$-PbO, tetragonal crystal structure), Figure 13.1. Lead white was identified through its characteristic band at $1049 \mathrm{~cm}^{-1}$ related to the $v 1$ stretching mode of the $\mathrm{CO}_{3}{ }^{2-}$ anion, ${ }^{1}$ whereas massicot and litharge were identified through their characteristic bands related to the $\mathrm{Pb}-\mathrm{O}$ vibrational modes at 143, 289 and $385 \mathrm{~cm}^{-1}$, and 145, 285 and $336 \mathrm{~cm}^{-1}$, respectively, ${ }^{2}$ Figure 13.1.

\footnotetext{
†SEM-EDS analyses were performed with a scanning electron microscope HITACHI 3700N coupled to an energy dispersive X-ray spectrometer BRUKER Xflash 5010. The analyses were made at $20 \mathrm{kV}$ with variable pressure (40 Pa).

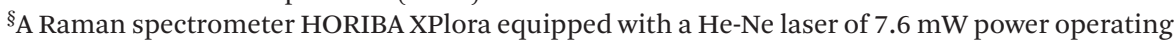
at $638 \mathrm{~nm}$, coupled to an Olympus microscope was used for the analysis of the paint's cross sections. Raman spectra were acquired in extended mode in the $100-1100 \mathrm{~cm}^{-1}$ region. The laser was focused with an Olympus $50 \times$ lens, with $0.76 \mathrm{~mW}$ laser power on the sample surface (5 seconds of exposure, 5 cycles of accumulation).
} 


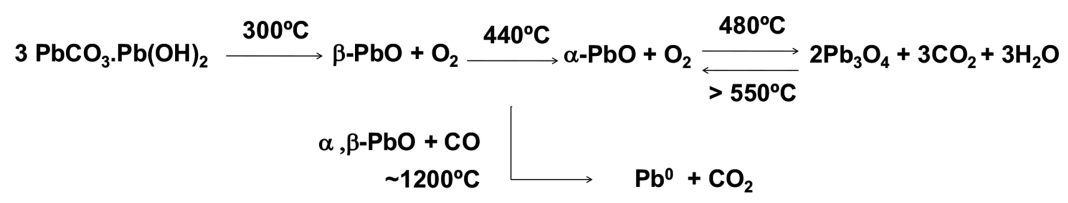

Figure 13.2 Heating process of lead white..$^{1-3}$
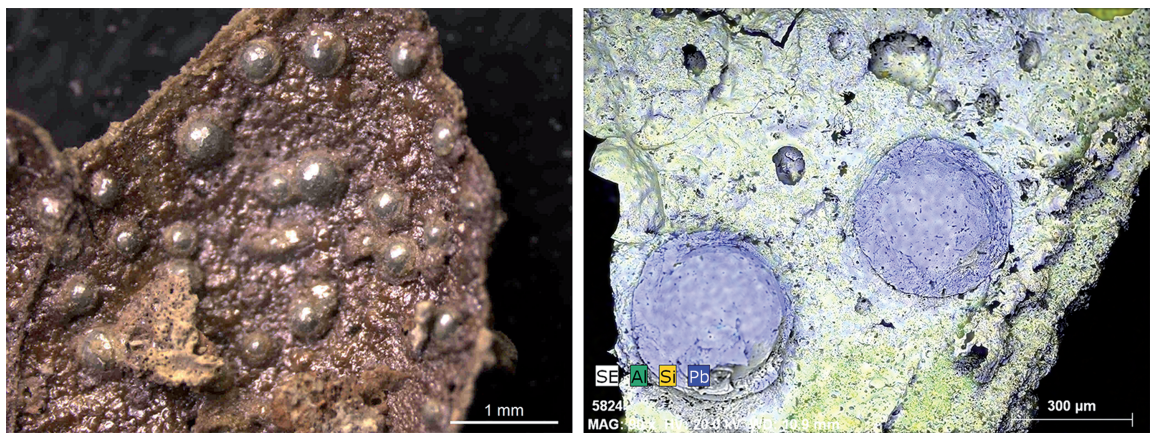

Figure 13.3 The influence of a severe in-situ heating process over lead-based paints elucidated by the surface view results acquired by OM and SEM-EDS (left and right, respectively).

Lead white is the white pigment par excellence of art history paintings from the Roman period onwards. ${ }^{1,3}$ Its replacement by less toxic materials such as zinc and titanium-based pigments only occurred in the 19th-20th century. When exposed to high temperatures in the presence of oxygen, lead carbonate is transformed into lead oxides (massicot, $\beta$-PbO, yellow-orange; litharge, $\alpha-\mathrm{PbO}$, orange-reddish; and read lead, $\mathrm{Pb}_{3} \mathrm{O}_{4}$, bright orange) following the heating process described in Figure 13.2.

Under the influence of severe heating conditions as those present in a fire (absence of oxygen and high temperatures), massicot and litharge are transformed into metallic lead and carbon dioxide, Figure 13.2. Fingerprints of this heating profile were observed by optical microscopy and SEM-EDS analysis, namely the presence of metallic lead and inner lacunas, where before $\alpha$ and $\beta$-lead oxides were placed, Figure 13.1 (the inset) and Figure 13.3.

In this approach, Raman microscopy was essential for the identification of lead white (the white pigment in use during the period of the painting's production) and of its resultant heating products massicot and litharge. Additionally, the inexistence of any other components that might have only been used in a later period than the 17 th century (such as zinc and titanium in its oxide forms or in its resultant heating products), allowed us to infer the originality of the ashes recovered from the fire of the Church. 


\subsection{Authenticity Evaluation of an Artwork Intercepted in the Trade Markets}

The importance that Man has always attributed to art and to artworks is well documented in the earliest testimonies of artworks that have survived. If, for the ancients, the trade value of an artwork was deeply related to its quality and with the importance of the materials used in the artwork's production, today, an artwork has become more of an investment and is increasingly dependent on the authorship and not the quality of the production techniques. In this sense, art and antique trading is now more of an investment asset, than simply art lovers' acquisitions. Today, the economic importance of the antique market is well reflected in the global economic system, attracting international buyers and large investments. The subject of this study concerns the evaluation of a rock crystal (quartz) Indo-Portuguese sculpture's authenticity attributed to the 17 th century (Figure 13.4). ${ }^{\top}$ In this sculpture, Infant Jesus is represented stood up on a sphere as a sign of His protection over the World. The representation is settled on a tetrahedral base, all the components being integrated as an apparently unique set (Figure 13.4). As a silicon-oxygen composed mineral, quartz presents a tetrahedral structure of $\mathrm{SiO}_{4}$ with two polymorphs (the trigonal $\alpha$-quartz - the most common polymorph; and the hexagonal $\beta$-quartz, which results from an inversion of $\alpha$-quartz when exposed to temperatures above $\left.570{ }^{\circ} \mathrm{C}\right) .{ }^{3}$ Hyaline quartz (known as rock crystal), is the purest form of quartz. Due to its transparency and brightness, rock crystal was commonly used in jewellery production. In this sense, the value inherent to this sculpture strongly depends on the material used for its production (whether this might have been rock crystal or simply glass), as it might be a reference for the time of production and, thus, for its authenticity. Raman microscopy" was used with the aim of evaluating the crystallographic origin of the entire sculpture. Several points on the base and on the right leg of the sculpture were analysed, aiming at characterising and evaluating the homogeneity of the material used to produce the sculpture (Figure 13.4).

Raman analysis of the tetrahedral base of the sculpture enabled the identification of some of the Raman bands characteristic of $\alpha$-quartz (rock crystal), namely the bands at 205 and $466 \mathrm{~cm}^{-1}$ bands ${ }^{4}$ (Figure 13.4 - red spectrum). To corroborate this result, a sample of natural rock crystal was analysed

\footnotetext{
"As this study was performed as part of a police investigation, we are not allowed by the authorities to present a visual image of the sculpture. Therefore, an X-ray image of the sculpture is presented.

"A Raman HORIBA XPlora spectrometer coupled to an Olympus microscope equipped with a diode laser of $20 \mathrm{~mW}$ power operating at $785 \mathrm{~nm}$, was used. The laser beam was focused with an Olympus $50 \times$ lens with a laser power on the sample surface of $2.0 \mathrm{~mW}$ (10 seconds of exposure, 10 cycles of accumulation). Raman spectra were acquired in an extended mode in the 100-1000 $\mathrm{cm}^{-1}$ region. To ensure the representativeness of the results, in each section, three different areas were always analysed. The spectra here presented are representative of those obtained for each analysed section.
} 


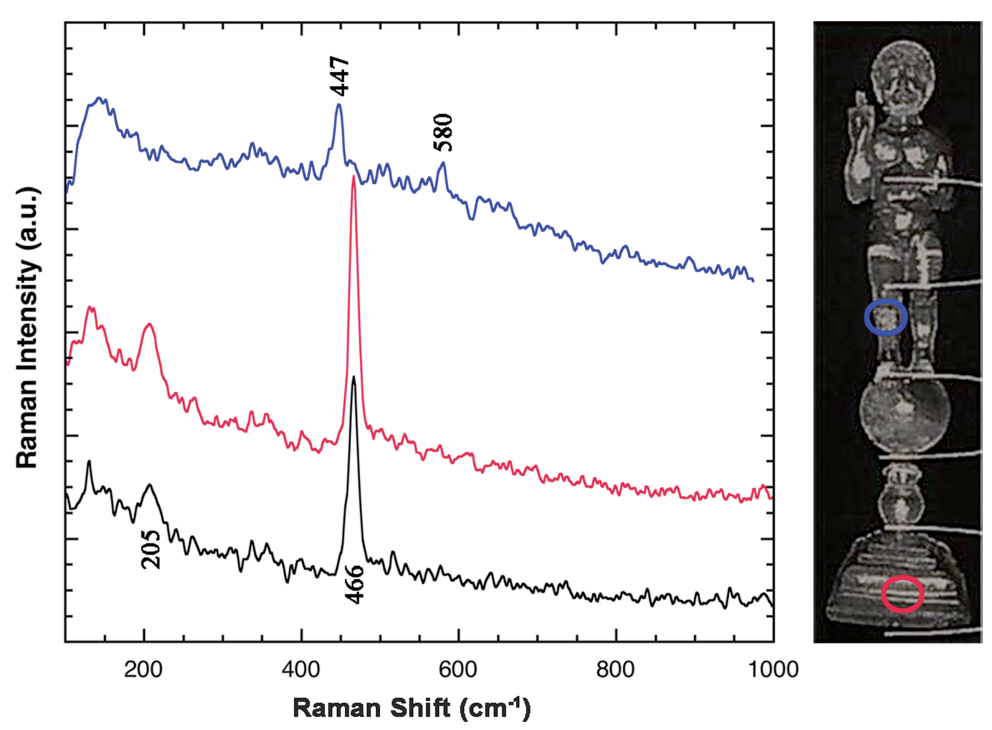

Figure 13.4 RM spectra of two spots analysed: the tetrahedral base where the characteristic Raman bands of rock crystal (red spectrum) were identified, and Infant Jesus' right leg, where the characteristic Raman bands of glass (blue spectrum) were identified. The black spectrum resulted from the analysis of a rock crystal used as a pattern. Right, X-ray image of the Infant Jesus sculpture and the regions analysed by Raman microscopy.

under the same conditions used for the analysis of the sculpture, enabling us to identify the same characteristic Raman bands (Figure 13.4 - black and blue spectra). On the other hand, the analysis of the right leg of the sculpture presents a lower Raman shift for the higher intense Raman band of $\alpha$-quartz (now placed at $447 \mathrm{~cm}^{-1}$ ) and a low intense Raman band at $580 \mathrm{~cm}^{-1}$ (Figure 13.4 - blue spectrum). According to Ribeiro et al., this low intense band might be related to the bending mode of the tetrahedral networks of $\left[\mathrm{SiO}_{4}\right]$ in a glass matrix that shift and the changes of intensity are directly related to the alterations on the tri-dimensional silica network caused by the glass manufacturing process. ${ }^{5}$

In this sense, the RM results enabled to us identify the use of two different materials in the sculpture's composition: rock crystal for the tetrahedral base and a high, pure, manufactured glass for the remaining sculpture. In the same line, the analysis of X-ray diffractograms ${ }^{* *}$ enabled us to verify that the base was composed of a crystalline material compatible with quartz crystal while the body of the sculpture was composed of an amorphous material

\footnotetext{
**X-ray diffractograms were acquired with an X-ray Microdiffractometer BRUKER Discovery in the $10^{\circ}<2 \theta<75^{\circ}$ range with a step width of $0.05^{\circ}$.
} 


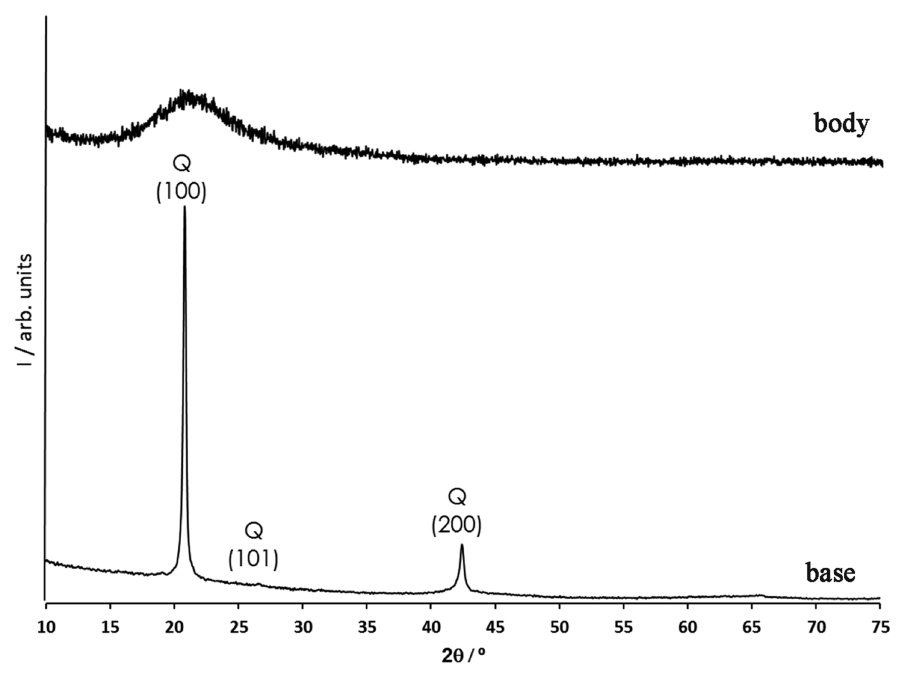

Figure 13.5 XRD diffractograms of both spots analysed by Raman microscopy see Figure 13.4. On the analysis of the tetrahedral base, a crystalline structure compatible with quartz crystal was found, while in the analysis of Infant Jesus' right leg, an amorphous crystalline structure typical of silica glass was found ( $\mathrm{Q}$ - indexing of quartz).

based on silica (a broadband is obtained in the position corresponding to plane 100 of the quartz, typical of silica glass), Figure 13.5.

Moreover, the fact that SEM-EDS did not detect other elements except silicon and oxygen in the glass matrix reflects the production of a glass without the use of fluxing agents (such as sodium or potassium) or stabilisers (such as calcium or lead), allowing us to conclude that silica glass was used for the production of the body of the sculpture. The melting temperature required to obtain silica glass (composed of silicon and oxygen) of $1650{ }^{\circ} \mathrm{C}$ was only possible with the technological developments achieved during the 20 th century. It is, thus, reasonable to state that this Infant Jesus sculpture is not of 17 th century production (as it is made of a modern glass), despite the tetrahedral of rock crystal base, which might have been sculpted during this period.

\subsection{Unveiling the Placement's Authenticity of Early Brazilian Printed Stamps Through Raman Microscopy}

The second country to introduce the use of postage stamps was Brazil, on 1st August, 1843, with postage rates established for land and sea routes: 60 reis for a letter carried by land weighing up to 4 oitavas (around half-ounce) and double the land rate for mail carried by ship. ${ }^{6}$ For these first printed stamps 

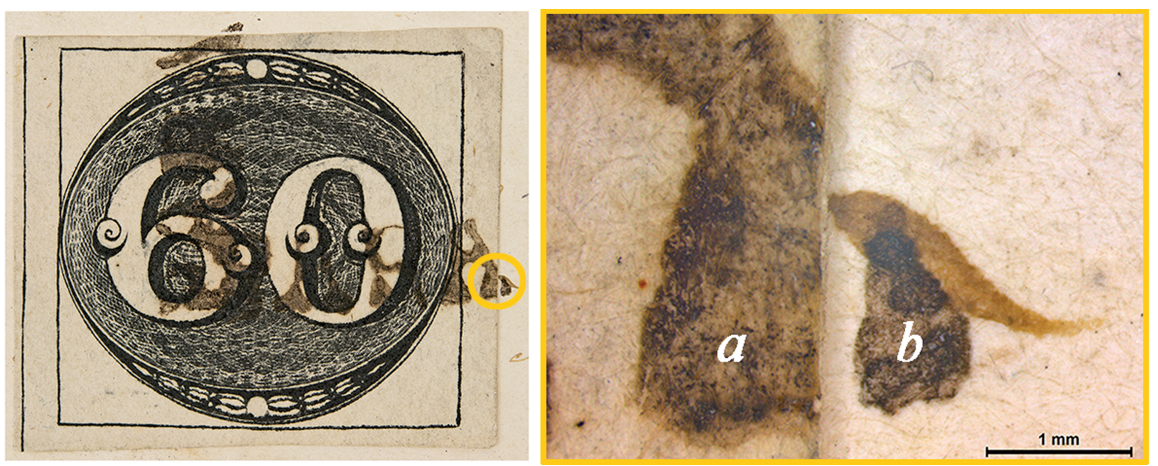

Figure 13.6 The 60 reis Brazilian Bull's eye stamp and the region analysed by Raman microscopy. Right, magnified image of the analysed region: (a) detail of the black postmark on the stamp; $(b)$ extension of the same black postmark over the envelope. Stamp reproduced with permission from F. Vasconcelos.
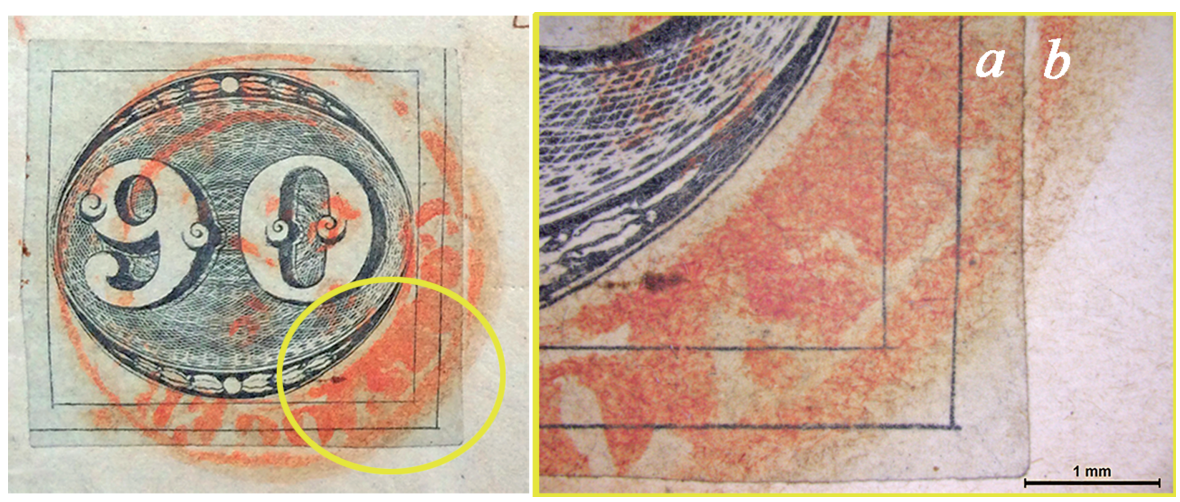

Figure 13.7 The 90 reis Brazilian Bull's eye stamp and the region analysed by Raman microscopy. Right, magnified image of the analysed region: $(a)$ detail of the red postmark on the stamp; $(b)$ extension of the same red postmark over the envelope. Stamp reproduced with permission from F. Vasconcelos.

- Bull's eyes for its resemblance to the animal's eyes - three values were printed: 30, 60 and 90 reis. The printing of Bull's eyes stamps ceased at the end of 1843 , being replaced by the slanted numeral stamp style. ${ }^{7}$ The value behind the trading of primitive stamps is highly dependent on the conservation condition and original placement: if a primitive stamp is found on its original envelope, its price increases expressively. This work involves the study of two Brazilian Bull's eye stamps to evaluate the authenticity of their original placements: a 60 reis Bull's eye stamp with a black postmark on it (Figure 13.6) and a 90 reis Bull's eye stamp with a red postmark on it (Figure 13.7). 


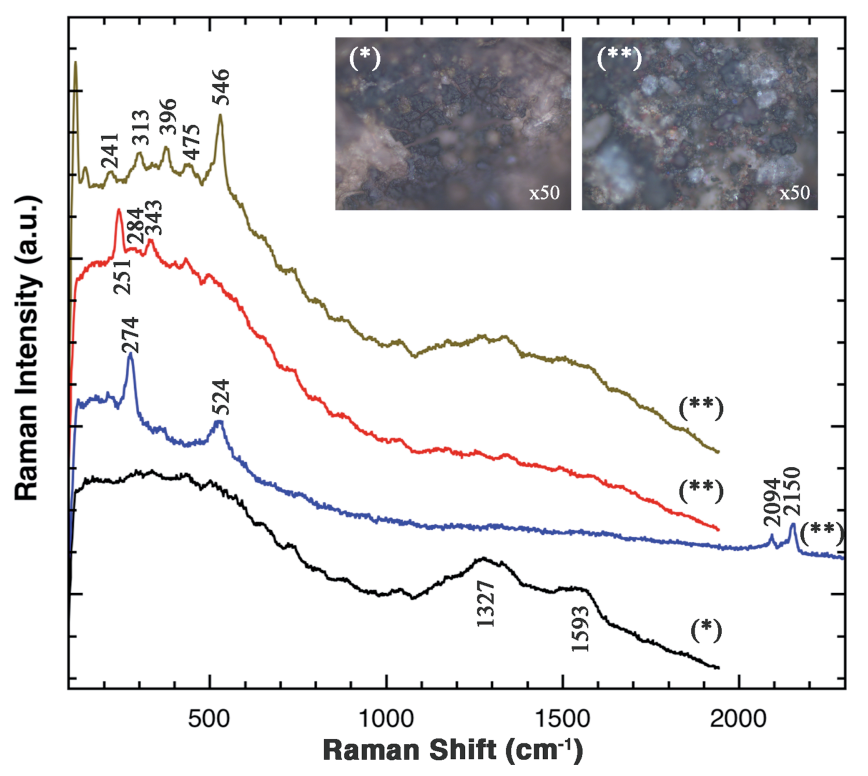

Figure 13.8 RM spectra of the two different regions of the postmark: $\left({ }^{*}\right)$ on the 60 reis stamp; $(* *)$ on its extension over the envelope. The inset shows magnified images of both regions where different surface and grains heterogeneities are found.

Raman $^{\dagger \dagger}$ analysis was performed on different regions of both postmarks, both on the stamp (Figures 13.6a and 13.7a) and on its extension over the envelope (Figures $13.6 b$ and $13.7 b$ ). RM analysis of the postmark on the 60 reis stamp allowed us to identify the characteristic Raman bands of carbon black, namely its characteristic broad doublet at $1593 \mathrm{~cm}^{-1}$, assigned to the $\mathrm{sp}^{2} \mathrm{C}-\mathrm{C}$ bonds, and at $1327 \mathrm{~cm}^{-1}$ assigned to the $\mathrm{sp}^{3} \mathrm{C}-\mathrm{C}$ bonds of graphite (Figure 13.8 - black spectrum). The intensity ratio of these two bands might be related to the disorder or crystallinity degrees of the samples. ${ }^{9}$ In this case, a carbon black of animal origin might have been used, as the higher contribution from the $\mathrm{sp}^{3} \mathrm{C}-\mathrm{C}$ bonds of graphite (at $1327 \mathrm{~cm}^{-1}$ ) reflects a higher disorder of the graphite structure (contrary to what is found for carbon blacks of vegetable origin, where a more intense contribution from the $\mathrm{sp}^{2} \mathrm{C}-\mathrm{C}$ bonds is present ${ }^{9}$ ).

Regarding the analysis of the black postmark extension over the envelope (Figure 13.6b), a different material composition was found, as in this region the stamp ink was not produced with carbon black, but by mixing

\footnotetext{
${ }^{\dagger}$ A Raman HORIBA XPlora spectrometer coupled to an Olympus microscope equipped with a diode laser of $20 \mathrm{~mW}$ power operating at $785 \mathrm{~nm}$, was used. The laser beam was focused with an Olympus $50 \times$ lens with a laser power on the sample surface of $2.0 \mathrm{~mW}$ ( 10 seconds of exposure, 10 cycles of accumulation). Raman spectra were acquired in extended mode in the $100-2300 \mathrm{~cm}^{-1}$ region.
} 
vermilion with goethite and Prussian Blue. In this sense, mercury sulfide was identified through its characteristic bands at $343 \mathrm{~cm}^{-1}$ attributed to the $v(\mathrm{Hg}-\mathrm{S})$ stretching, and to the bands at 251 and $284 \mathrm{~cm}^{-1}$ ascribed to the $\delta(\mathrm{S}-\mathrm{Hg}-\mathrm{S})$ angle bending ${ }^{10}$ (Figure 13.8 - red spectrum). Goethite, the brown iron oxide $\alpha-\mathrm{FeO}(\mathrm{OH})$, was identified through its characteristic Raman bands at 241, 313, 396, 475, $546 \mathrm{~cm}^{-111}$ (Figure 13.8 - brown spectrum). Prussian blue, $\left(\mathrm{Fe}_{4}\left[\mathrm{Fe}(\mathrm{CN})_{6}\right]\right)$, was identified through its characteristic Raman bands at 274, 524 and $2094 \mathrm{~cm}^{-1}$, together with its characteristic $(\mathrm{C} \equiv \mathrm{N})$ stretching vibration at $2150 \mathrm{~cm}^{-112,13}$ (Figure 13.8 - blue spectrum). The differences of the materials identified in both regions of the postmark contradicted the statements of authenticity declared previously by some philately experts. Again, as in the previous case study presented in this chapter, Raman microscopy was revealed to be crucial to unveiling the truth behind what, to the naked eye, seemed to be an original philatelic object.

Regarding the analysis of the 90 reis stamp, its observation under magnification (Figure 13.7, right) evidenced the presence of a yellowish matrix on which a reddish component is dispersed. RM analysis of this reddish component consistently identified the characteristic Raman bands of vermilion $(\alpha-\mathrm{HgS})$ at 252, 284 and $342 \mathrm{~cm}^{-1},{ }^{10}$ Figure 13.9.

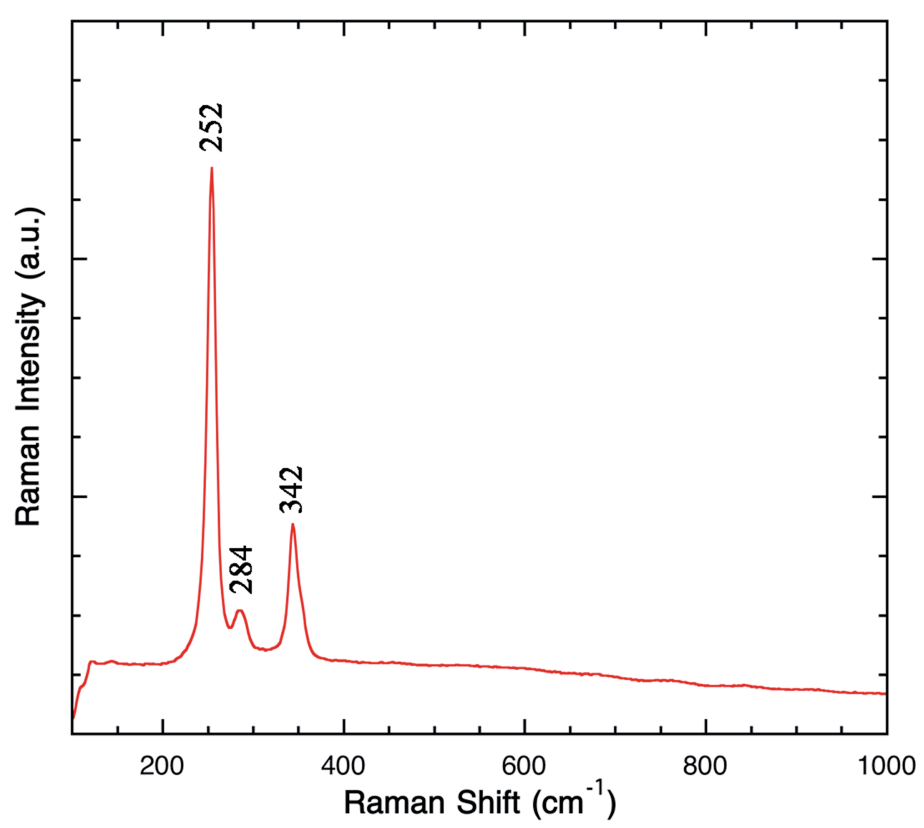

Figure 13.9 Representative Raman spectrum analysis of the postmark red ink on the envelope and on the stamp, where the characteristic Raman bands of vermilion $(\alpha-\mathrm{HgS})$ can be identified. 


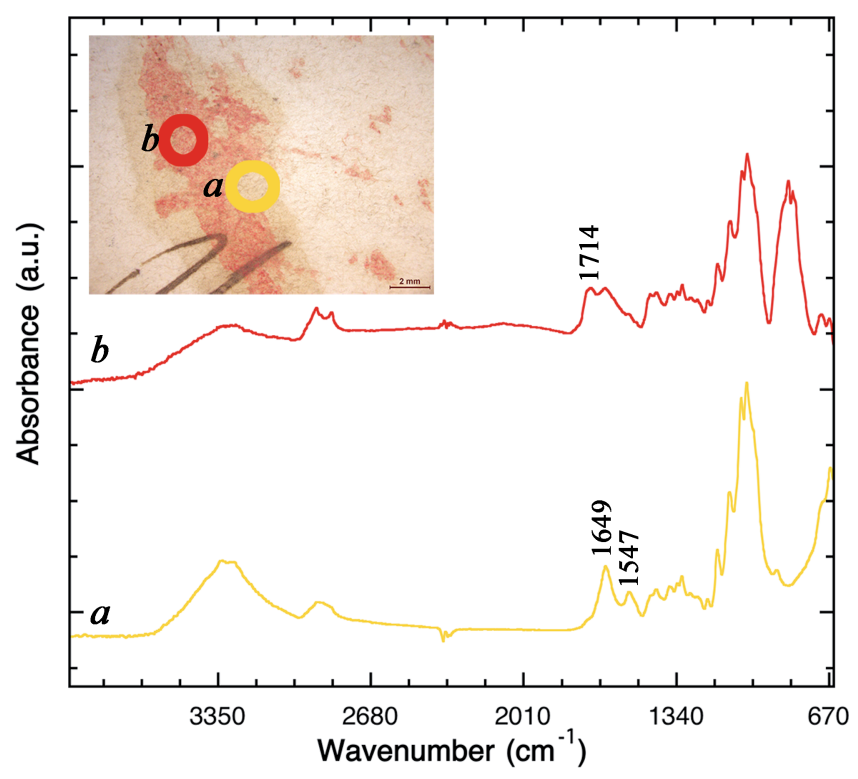

Figure 13.10 Representative infrared spectra of the yellowish $(a)$ and red $(b)$ components present in the postmark ink, where it is possible to identify the absorption bands related to a proteinaceous binder (1649 and $\left.1547 \mathrm{~cm}^{-1}\right)$ and to an oxidised triglyceride-based component (1714 $\mathrm{cm}^{-1}$ ) on the paint's formulations. The inset shows a magnified image highlighting the spots of analysis.

FTIR-ATR ${ }^{+1}$ analysis of the yellowish matrix allowed us to identify - besides the characteristic absorption bands of cellulose of the envelope - the characteristic absorption bands of a proteinaceous binder (namely the bands at 1649 and $\left.1547 \mathrm{~cm}^{-1}\right),{ }^{14}$ Figure $13.10 a$. On the other hand, IR spectra of the red ink component present - besides the bands related to cellulose and the presence of a protein - an infrared absorption band at $1714 \mathrm{~cm}^{-1}$, characteristic of carbonyl groups of carboxylic acids ${ }^{14}$ Figure $13.10 \mathrm{~b}$. This, together with the CH's absorption bands' profile at $3000-2840 \mathrm{~cm}^{-1}$ of the infrared region, suggests the presence of an oxidised triglyceride-based component in the reddish component formulation.

It is possible that the ink used for the postmark has been separated into its organic constituents during its drying process, where the pigment $(\alpha$ $\mathrm{HgS}$ ) remained more agglutinated to the triglyceride component (although in this fraction the presence of some proteinaceous material is also

\footnotetext{
${ }^{*}$ An infrared spectrometer BRUKER Hyperion 3000 equipped with a single point MCT detector cooled with liquid nitrogen and a 20× ATR objective with a Ge crystal of $80 \mu \mathrm{m}$ diameter were used. Infrared spectra were acquired with a spectral resolution of $4 \mathrm{~cm}^{-1}, 32$ scans, in the $4000-650 \mathrm{~cm}^{-1}$ of the infrared region.
} 
identified), whereas the surrounding region (yellowish ink) remained more enriched in the proteinaceous binder initially present in the stamp ink's formulation. As these compositions were found either on the stamp and/or the region of interface on the seal-envelope, it became possible to infer the originality of the seal location, since the postmark is present continuously and in a non-uninterrupted way in the interface of the seal-envelope. Also, the homogeneity of the composition of red inks present in the envelope, as well as the yellowish matrix, corroborated this result. A shrinkage process in the drying process of the red ink used by the post offices might be the reason for the presence of these two-colour regions: a more external yellow ink - enriched with a proteinaceous-based component - and a more internal red ink, where the presence of the red pigment (vermilion), together with an oxidised triglyceride-based component and some proteinaceous binder were identified.

\subsection{Final Remarks}

Some of the results presented and discussed turned out to be surprising, once the molecular information contradicted the expected results by the owners and authorities who requested the analysis. For all of the results presented here, complementary analytical techniques were used to corroborate the molecularity identified by Raman microscopy, reflecting the robustness of the technique and its usefulness for forensic research.

\section{References}

1. R. J. Gettens, H. Kühn and W. T. Chase, Lead white, in Artists' Pigments - A Handbook of Their History and Characteristics, ed. A. Roy, Oxford University Press, New York, 1993, vol. 2, pp. 67-81.

2. C. Miguel, L. Dias, J. Mirão and A. Candeias, Meant to be discovered: the study by microscopic analysis of lead-based pigments alteration by a fire, Microsc. Microanal., 2015, 21(Suppl. 5), 29-30.

3. N. Eastaugh, V. Walsh, T. Chaplin and R. Siddall, The Pigment Compendium - A Dictionary of Historical Pigments, Elsevier Butterworth-Heinemann, Burlington, 2004.

4. H. G. M. Edwards and J. M. Chalmers, Raman Spectroscopy in Archaeology and Art History, Royal Society of Chemistry, 2005, vol. 9, p. 457, ISBN: 9780854045228.

5. I. M. N. Ribeiro, R. P. Freitas, C. Calza, A. L. C. Oliveira, V. S. Felix and D. S. Ferreira, et al., Analysis by Raman spectroscopy and XRF of glass beads from excavations in the harbor area of rio de janeiro, Brazil, Vib. Spectrosc., 2016, 87, 111-115.

6. S. R. Trepel, The Islander Collection - The Rarest and Most Outstanding Stamps of South America, Robert A. Siegel Auction Galleries, Inc, New York, 2008. 
7. J. Watson, The Stanley Gibbons Book of Stamps and Stamp Collecting, Crescent Books, New York, 1981.

8. S. Rada, A. Dehelean and E. F. T. I. R. Culea, Raman, and UV-Vis spectroscopic and DFT investigations of the structure of iron-lead-tellurate glasses, J. Mol. Model., 2011, 17, 2103-2111.

9. E. P. Tomasini, E. B. Halac, M. Reinoso, E. J. Liscia and M. S. Maier, Micro-Raman spectroscopy of carbon-based black pigments, J. Raman Spectrosc., 2012, 43, 1671-1675.

10. R. L. Frost, H. G. M. Edwards, L. Duong, J. T. Kloprogge and W. N. Martens, Raman spectroscopic and SEM study of cinnabar from Herod's palace and its likely origin, Analyst, 2002, 127, 203-296.

11. D. L. A. Faria, S. Venancio-Silva and M. T. de Oliveira, Raman microspectroscopy of some iron oxides and oxyhydroxides, J. Raman Spectrosc., 1997, 28, 873-878.

12. K. Castro, P. Vandenabeele, M. D. Rodríguez-Laso and J. M. Madariaga, Micro-Raman analysis of coloured lithographs, Anal. Bioanal. Chem., 2004, 379(4), 674-683.

13. P. Vandenabeele, P. Paepe and L. Moens, Study of the 19th century porcelain cards with direct Raman analysis, J. Raman Spectrosc., 2008, 39(8), 1099-1103.

14. M. Derrick, D. Stulik and J. M. Landru, Infrared Spectroscopy in Conservation, The Getty Conservation Institute, Los Angeles, 1999. 